Technical Note

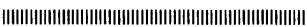

\title{
Effects of Phantom Size and Material on Calibration of Photon Individual Dosimeters ${ }^{\dagger}$
}

\author{
Fumiaki TaKahashi, Michio Yoshizawa \\ and Yasuhiro YAMAGUCHI \\ Department of Health Physics, Tokai Research Establishment, \\ Japan Atomic Energy Research Institute \\ 2-4, Shirakata-Shirane, Tokai-mura, Naka-gun, Ibaraki Pref. 319-11, Japan
}

Received August 21, 1997

\begin{abstract}
Backscattered photons from slab phantoms were analyzed to investigate the effects of phantom size and material on calibration of dosimeters. The backscatter factor estimated by measurement with an ionization chamber was compared for three different phantoms; a $40 \times 40 \times 15 \mathrm{~cm}^{3}$ polymethyl methacrylate (PMMA) phantom, a $30 \times 30 \times 15 \mathrm{~cm}^{3} P M M A$ phantom and a water-filled phantom recommended by the International Organization for Standardization (ISO). Monte Carlo calculations using EGS4 code were also performed to examine the measured results and to analyze the effect of phantom size and material on the dosimeter calibration. It was found that the ISO phantom could give up to $10 \%$ higher value of calibration factor than the $40 \times 40 \times 15 \mathrm{~cm}^{3} P M M A$ phantom, now commonly used in Japan, for photons of $60 \mathrm{keV}$.
\end{abstract}

Key Words: slab phantom, individual dosimeter, calibration, ionization chamber, Monte Carlo calculation, EGS4 code

\section{Introduction}

Photon individual dosimeters need to be calibrated on an appropriate phantom that can provide a reasonable approximation to backscatter properties of the human body on which they are worn. The International Commission on Radiation Units and Measurements (ICRU) has recommended the use of a $30 \times 30 \times 15 \mathrm{~cm}^{3}$ polymethyl methacrylate (PMMA) phantom for the dosimeter calibration ${ }^{1)}$, because its mass is close to that of the four-element ICRU sphere and its backscatter feature is similar to that of the human

\footnotetext{
†ファントムの寸法および材質が光子個人線量計 校正に与える影響。高橋史明, 吉澤道夫, 山口 恭弘: 日本原子力研究所東海研究所保健物理部, 319-11 茨城県那珂郡東海村白方白根 2-4。
}

trunk for photon irradiation. The International Organization for Standardization (ISO) has also suggested a $30 \times 30 \times 15 \mathrm{~cm}^{3}$ water-filled phantom which has a $2.5 \mathrm{~mm}$ thick PMMA front face and $1 \mathrm{~cm}$ thick PMMA walls (ISO phantom) $)^{2}$. The ISO phantom is now being internationally accepted, because the difference in backscattering between the phantom made of ICRU tissue and the ISO phantom can be neglected ${ }^{3)}$.

The Japan Industrial Standard (JIS), on the other hand, has recommended the use of a $40 \times 40$ $\times 15 \mathrm{~cm}^{3}$ PMMA phantom for photon dosimeter calibration. Since backscattered photons significantly contribute to the dosimeter response, depending on phantom size and material, the backscatter feature needs to be investigated for the phantoms nationally and internationally recommended. 
In the present work, the exposure rate was measured with an ionization chamber on the three phantoms mentioned above and the contribution of backscattered photons to the dosimeter response was investigated. Monte Carlo calculations using the Electron-Gamma Shower Code Version 4 (EGS4) ${ }^{4)}$ were also performed to analyze the backscattered photons at the surface of PMMA phantoms with different frontal dimensions and the ISO phantom.

\section{Methods}

\subsection{Measurements}

Exposure rates were measured on the surface of the two PMMA phantoms of different size (40 $\times 40 \times 15 \mathrm{~cm}^{3}$ and $30 \times 30 \times 15 \mathrm{~cm}^{3}$ ) and the ISO phantom with a cylindrical ionization chamber (Victoreen, Mod. 550-4-T) as seen in Fig. 1. The ionization chamber has a radius of $1.2 \mathrm{~cm}$, length of $7.2 \mathrm{~cm}$ and volume of $33 \mathrm{~cm}^{3}$.

An X-ray generator and two gamma-ray sources of ${ }^{137} \mathrm{Cs}$ and ${ }^{60} \mathrm{Co}$ were used for photon irradiation. The effective energy of filtrated X-rays ranged from $32 \mathrm{keV}$ to $200 \mathrm{keV}$. The ratio of the effective energy to the maximum energy of the $\mathrm{X}$-ray spectra (Quality Index) was between 0.79 and 0.81 . The $\mathrm{X}$ - and gamma-rays were collimated into a conical beam.

The surface of the phantom was $2.5 \mathrm{~m}$ distant from the target of the X-ray generator or the

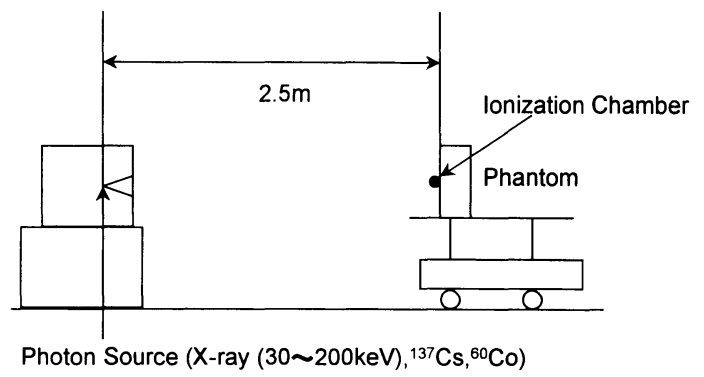

Fig. 1 Overview of irradiation and measurement. gamma-ray source. The distance between the center of the ionization chamber and the phantom surface was fixed to be $1.5 \mathrm{~cm}$, because the front face of the ISO phantom swell little by little due to water pressure during the measurement.

The measurements of exposure rate were also made in free air to obtain the proportion of the backscattered radiations from the phantoms.

The uncertainties in the measurements were estimated within $4 \%$.

\section{$2 \cdot 2$ Calculations}

Monte Carlo calculations using the EGS4 code were performed to analyze the measured results. The photon cross section data taken from the library of Trubey ${ }^{5)}$ were used in the photon transport calculations. The track length estimator was employed to calculate the exposure on the surface of the phantoms and in free air. The position and volume of the estimator were approximated to the ionization chamber used in the measurement. The phantom normally faced to a broad parallel beam of photons. The energy distribution of incident $\mathrm{X}$-ray beams was also consistent with that used in the experiment.

Additional calculations were performed to analyze the effect of the phantom size and material on the dosimeter calibration. The size of front square surface was changed by $5 \mathrm{~cm}$ from $20 \mathrm{~cm}$ to $50 \mathrm{~cm}$. The spectral distribution of exposure was calculated at the surface of the PMMA phantoms and the ISO phantom for the incidence of the monoenergetic photon beams of $60 \mathrm{keV}$ and $662 \mathrm{keV}$

The statistical uncertainties in the calculations were within $1 \%$ for the exposure rate and within $2 \%$ for the exposure rate in each energy bin.

\section{Results}

All the measured and calculated results will be 
expressed in terms of backscatter factor, $B_{\mathrm{F}}$, defined as below.

$$
B_{\mathrm{F}}=\boldsymbol{X}_{\text {on phantom }} / \boldsymbol{X}_{\text {in free air }}
$$

where,

$X_{\text {on phantom }}$ : the exposure rate on the phantom, and

$X_{\text {in free air }}:$ the exposure rate in free air at the same position of $\boldsymbol{X}_{\text {on phantom. }}$

Figure 2 shows the energy dependence of the backscatter factor for the three different phantoms. The calculated $B_{\mathrm{F}}$ values of the PMMA phantoms are larger than the measured ones. Since the radiations scattered by the table or the walls in the calibration room were not included in the calculation, the difference between calculated and measured $\boldsymbol{B}_{\mathrm{F}}$ values may be attributed to this neglect and the measured values are considered to be smaller than the measured ones. The backscatter factor is seen to depend significantly on the incident photon energy. While a significant difference of the $B_{\mathrm{F}}$ value can be seen between the three phantoms for photons below $150 \mathrm{keV}$, it can be neglected for photons above $300 \mathrm{keV}$. This means that the size or material of the phantom is

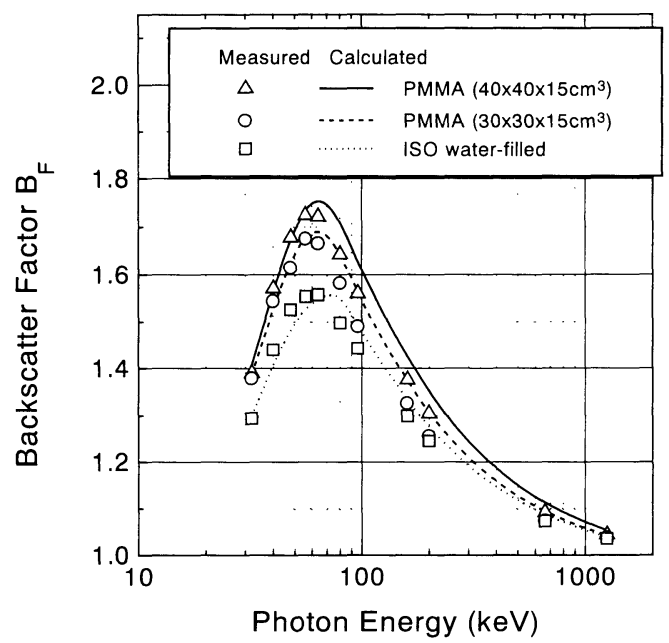

Fig. 2 Backscatter factor for the three recommended phantoms as a function of incident photon energy. a substantial factor of the $B_{\mathrm{F}}$ value for photons below $150 \mathrm{keV}$.

\section{Discussion}

\section{1 Effect of phantom size}

Figure 3 shows the relationship between the $\boldsymbol{B}_{\mathrm{F}}$ value and the frontal dimension of the PMMA phantom. The number of the scattered photons from the phantom increases with the frontal dimension for all photon energies, especially in the energy region between $50 \mathrm{keV}$ and $100 \mathrm{keV}$. The $40 \times 40 \times 15 \mathrm{~cm}^{3}$ PMMA phantom can give $4 \%$ larger response of dosimeter than the $30 \times 30 \times 15$ $\mathrm{cm}^{3}$ PMMA phantom for photons of $64 \mathrm{keV}$.

\subsection{Spectral distribution at the surface of the phantoms}

Figures 4 and 5 show spectral distributions of exposure rate at the surface of the phantoms for monoenergetic broad parallel beams of $60 \mathrm{keV}$ and $662 \mathrm{keV}$ photons, respectively. In the figures, the exposure due to photons with each incident energy of $60 \mathrm{keV}$ or $662 \mathrm{keV}$ is normalized to unity. While the phantom with different material

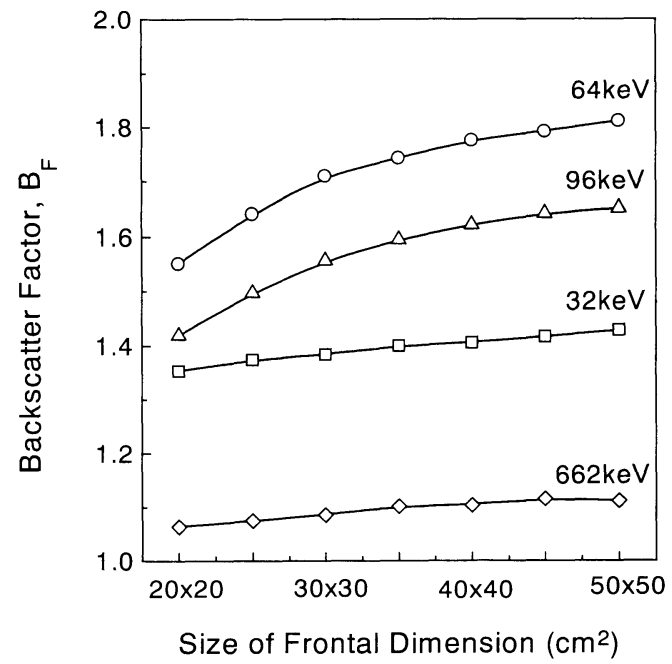

Fig. 3 Dependence of backscatter factor on phantom size for different photon energies. 


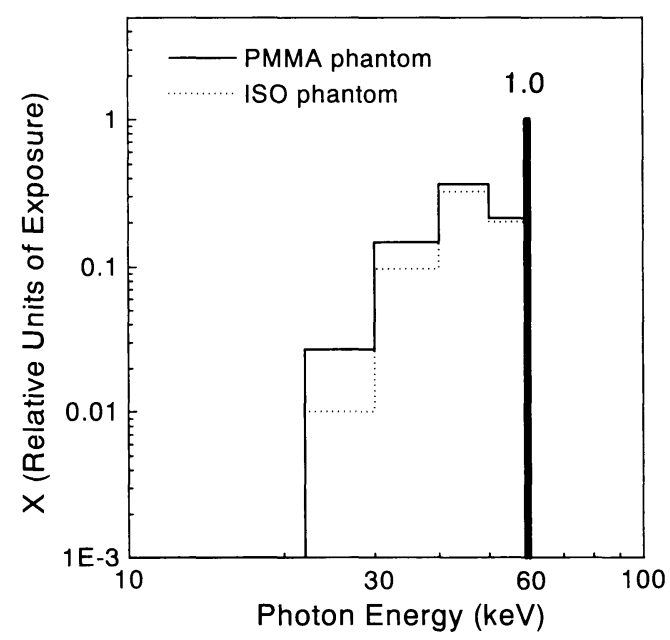

Fig. 4 Spectral distributions of exposure on the slab phantoms $\left(30 \times 30 \times 15 \mathrm{~cm}^{3}\right)$ for incidence of $60 \mathrm{keV}$ photons.

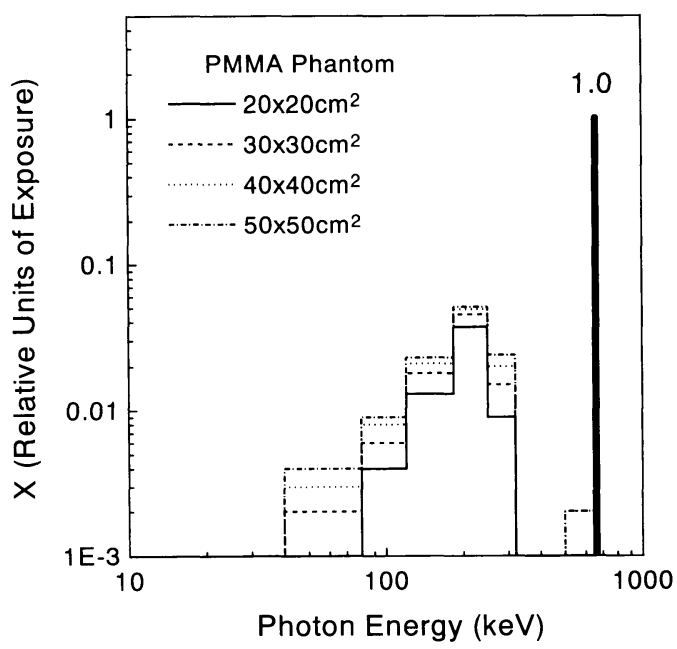

Fig. 5 Spectral distributions of exposure on the PMMA slab phantoms for incidence of $662 \mathrm{keV}$ photons.

gives different shape of energy spectra of the backscattered radiations, the different size of phantom gives different quotient of the backscattered radiations. The ratio of scattered photons to the total ones for a $50 \times 50 \times 15 \mathrm{~cm}^{3}$ PMMA phantom is up to $4 \%$ higher than that for a $20 \times 20 \times 15 \mathrm{~cm}^{3}$ PMMA phantom for $662 \mathrm{keV}$ photons. It can be concluded from Figs. 3 and 5 that a larger phantom can give a more enhanced dosimeter readings

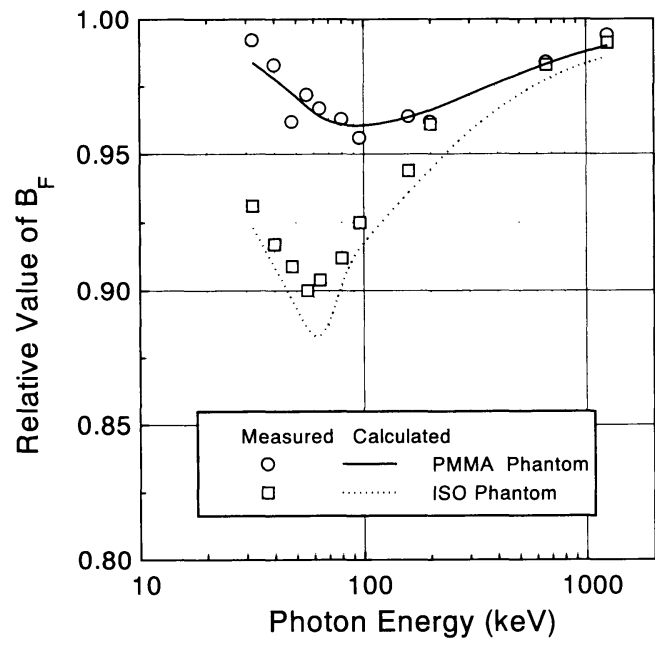

Fig. 6 Relative values of $B_{\mathrm{F}}$ for $30 \times 30 \times 15$ $\mathrm{cm}^{3}$ slab phantoms.

$B_{\mathrm{F}}$ value of $40 \times 40 \times 15 \mathrm{~cm}^{3}$ PMMA phantom $=1.0$.

due to the increase of backscattered radiations.

\section{4-3 Effect on dosimeter calibration}

Figure 6 clarifies the effect of the phantom size and material on the dosimeter calibration. The $B_{F}$ values of the two $30 \times 30 \times 15 \mathrm{~cm}^{3}$ slab phantoms are compared with that of the $40 \times 40 \times 15 \mathrm{~cm}^{3}$ PMMA phantom. A significant difference of $B_{\mathrm{F}}$ values can be seen between the ISO phantom and the two PMMA phantoms in the energy region below $100 \mathrm{keV}$. The measured $\boldsymbol{B}_{\mathrm{F}}$ value of the ISO phantom is $10 \%$ lower than that of the $40 \times 40 \times$ $15 \mathrm{~cm}^{3}$ PMMA phantom for photons of $60 \mathrm{keV}$.

Calibration factor, C.F., is obtained as below :

C. F. $=S / R$

$$
\begin{aligned}
& S: \text { Reference dose rate, and } \\
& R \text { : Reading of dosimeter. }
\end{aligned}
$$

The reading of the dosimeter on a phantom, $R$, increases linearly with the $B_{\mathrm{F}}$ value. Then, the ISO phantom can give higher C.F. value than the $40 \times$ $40 \times 15 \mathrm{~cm}^{3}$ PMMA phantom by up to $10 \%$. Thus, the dose values estimated by the individual dosimeters can be higher for low energy photon, if 
the ISO phantom supersede the PMMA phantom commonly used in Japan.

\section{Conclusions}

Our measurement and calculation showed that the phantom material is more influential than its frontal dimension in individual photon dosimeter calibration. The difference of backscattering feature between the ISO phantom and the PMMA phantoms should be considered. The response of the dosimeter on the ISO phantom is expected to be lower than that on the PMMA phantom, presently used in Japan. It should be emphasized here that the front face of ISO phantom swells gradually during the calibration and the position of the dosimeter on the phantom cannot be fixed. The most suitable thickness of PMMA front face or other material for walls of the phantom should be investigated, if water phantoms are adopted in the dosimeter calibration.

\section{References}

1) International Commission on Radiation Units and Measurements : Report 47 (1992)

2) International Organization for Standardization : ISO DIS4037 Pt3 (Draft), Geneva, Switzerland (1996)

3) Alberts, W. G., Ambrosi, P., Bohm, J., Dietze, G., Hohlfeld, K. and Will, W. : "New dose quantities in radiation protection”, PTB-Dos-23e (1995)

4) Nelson, W. R., Hirayama, H. and Rogers, D.W. O. : The EGS4 Code System, SLAC-265 (1985)

5) Trubey, D. K., Berger, M. J. and Hubbell, J. H. : "Photon Cross Sections for ENDF/B-VI", Advanced in Nuclear Computation and Radiation Shielding, American Nuclear Society Topical Meeting (1989) 